\title{
REFLEXIONES SOBRE EL ALCANCE DE LOS PRINCIPIOS DEL CAUSANTE Y DE CAPACIDAD CONTRIBUTIVA A LA LUZ DE LA TEORÍA DE LA TRIBUTACIÓN AMBIENTAL: LOS CASOS DE BRASIL Y COSTA RICA
}

\author{
Carlos E. Peralta \\ Universidad de Costa Rica, Costa Rica \\ carlosperalta07@gmail.com
}

RESUMEN: La introducción de la variable ambiental en el sistema tributario es objeto de debate en agendas políticas y en la doctrina jurídica. La tendencia es que en los próximos años la discusión sea más intensa y que figuras tributarias de carácter ecológico sean implementadas de manera más sistemática. El presente artículo pretende realizar algunas reflexiones críticas con respecto a los alcances de los principios del causante y de capacidad contributiva en la tributación ambiental, analizando su contenido y aspectos más controvertidos.

PALABRAS CLAVE: Extrafiscalidad. Tributación ambiental. Principio del causante. Principio de capacidad contributiva.

The principles of the polluter-pays and ability-to-pay according to the theory of environmental taxation: The cases of Brazil and Costa Rica

\begin{abstract}
The introduction of the environmental variable in the tax system is debated in politics and legal doctrine. The discussion will increase and more environmental taxes will be systematically implemented. The article will make critical reflections on the scope of the principles of the causer of environmental impact and taxable capacity in green taxation. The work will analyze its content and more controversial aspects.

KEYWORDS: Extra taxation. Environmental tax. Polluter-pays principle. Ability-to-pay principle.

Reflexões sobre o alcance dos princípios do poluidor-pagador e da capacidade contributiva a partir da teoria da tributação ambiental: Os casos do Brasil e da Costa Rica

RESUMO: A introdução da variável ambiental no sistema tributário é objeto de debate nas agendas políticas e na doutrina jurídica. Nos próximos anos, a tendência é que a discussão seja mais intensa e que os tributos ecológicos sejam adotados de maneira mais sistemática. Este artigo tem como objetivo fazer algumas reflexões críticas sobre o alcance dos princípios do poluidorpagador e da capacidade contributiva na tributação ambiental, analisando o seu conteúdo e os seus aspectos mais controversos.
\end{abstract}

PALAVRAS-CHAVE: Extrafiscalidade. Tributação ambiental. Principio do poluidor-pagador. Principio da capacidade contributiva. 
Reflexiones sobre el alcance de los principios del causante y de capacidad contributiva a la luz de la teoría de la tributación ambiental: los casos de Brasil y Costa Rica

\section{INTRODUCCIÓN}

La degradación ambiental es una característica y al mismo tiempo una consecuencia de un modelo de desarrollo pautado sobre la idea crecimiento económico continuo y que atiende únicamente a las leyes del mercado, desconociendo los límites biofísicos del planeta. Esa forma de entender el desarrollo ha ocasionado riesgos ecológicos de carácter transfronterizo, sinergético e intemporal, en un escenario de imprevisibilidad y de riesgo.

Dentro de ese marco, el Estado de Derecho deberá adquirir una vertiente ambiental que sea capaz de conciliar las diversas dimensiones de los derechos fundamentales dentro de un proyecto jurídico político para una sociedad más sustentable. Existe una necesidad de formular un Estado Ecológico de Derecho, capaz de incorporar nuevos valores e instrumentos orientados a una racionalidad ambiental que respete las fronteras de riesgo ecológico identificadas por los conocimientos científicos.

En ese marco, el derecho como estrategia institucionalizada que establece vínculos y límites con el objetivo de buscar el mayor bien estar de la sociedad, deberá ser capaz de analizar, comprender y adaptarse a los problemas ambientales que caracterizan el Antropoceno. Así, el derecho deberá repensar sus conceptos y estructura, y adoptar una visión prospectiva, permeada por una perspectiva de pensamiento complejo. El derecho deberá implementar mecanismos que permitan orientar, de forma sustentable, los procesos de extracción, distribución, producción, consumo y descarte, de forma que esas etapas sean realizadas sin causar un impacto desproporcional en la naturaleza que provoque daño ambiental.

Actualmente, se considera que instrumentos económicos de gestión ambiental son herramientas adecuadas para promover la sustentabilidad ambiental. Esos mecanismos, fundamentados en el principio del causante, permiten complementar los tradicionales mecanismos de comando y control; orientando a los agentes económicos, en sentido positivo o negativo, a adoptar prácticas ecológicamente correctas. Entre esos instrumentos se encuentra el tributo, a través de su función extrafiscal.

La introducción de la variable ambiental en el sistema tributario es objeto de debate en agendas políticas y en la doctrina jurídica. La tendencia es que en los próximos años la discusión sea más intensa y que figuras tributarias de carácter ecológico sean implementadas de manera más sistemática.

Teniendo en cuentas esas consideraciones, el presente artículo pretende realizar algunas reflexiones críticas con respecto a los alcances de los principios del causante y de capacidad contributiva en la extrafiscalidad ambiental, analizando su contenido y aspectos más controvertidos. La relevancia del estudio se deriva de que el primero de esos principios deberá ser parámetro orientador para una adecuada técnica tributaria en materia ambiental; mientras que el segundo principio, tradicionalmente empleado para definir los contornos de los tributos ordinarios, en la extrafiscalidad ambiental, encuentra su alcance limitado.

El análisis será realizando teniendo en cuenta la teoría general de la tributación ambiental, y haciendo breves referencias a la normativa de Brasil y Costa Rica sobre los citados principios. Además, el estudio pretende realizar propuestas concretas y sencillas, para introducir en los ordenamientos jurídicos de ambos países, la variable ambiental en los sistemas tributarios.

Para cumplir con los objetivos propuestos, el trabajo fue estructurado en tres partes:

1. En la primera parte se analiza el contenido del principio del causante como parámetro que orienta y delimita la extrafiscalidad ambiental; 
2. La segunda parte se avoca al estudio del contenido del principio de capacidad contributiva en la tributación y a la comprensión de su alcance en la tributación ambiental; y

3. Finalmente, en la tercera parte se exponen conclusiones sucintas derivadas de la investigación realizada.

\title{
1. EL PRINCIPIO DEL CAUSANTE COMO PARÁMETRO ORIENTA- DOR DE LA EXTRAFISCALIDAD AMBIENTAL
}

\subsection{Precisiones conceptuales sobre el principio del causante}

Las características propias de los bienes ambientales hacen que el mercado falle a la hora de distribuir bienes y servicios ambientales. Las fallas o distorsiones del mercado originan las externalidades ambientales - negativas o positivas - que sin una adecuada intervención acaban siendo soportadas por la colectividad.

El principio del causante ${ }^{1}$ tiene una dimensión económica, y se concreta en el ámbito jurídico como un parámetro que encuentra fundamento en el deber del Estado y de todos los ciudadanos de proteger el ambiente natural y de utilizar de forma sustentable los recursos naturales, como forma de garantizar la adecuada calidad ambiental y respetar criterios de justicia ecológica. De modo que, se trata de un principio orientador de las políticas públicas dirigidas a la búsqueda de la sustentabilidad.

El principio fue previsto en la Declaración de Rio sobre Medio Ambiente y Desarrollo, de 1992, en el Principio 16, estableciendo que

\begin{abstract}
Las autoridades nacionales deberían procurar fomentar la internalización de los costos ambientales y el uso de instrumentos económicos, teniendo en cuenta el criterio de que el que contamina debe, en principio, cargar con los costos de la contaminación, teniendo debidamente en cuenta el interés público y sin distorsionar el comercio ni las inversiones internacionales.
\end{abstract}

En Brasil, por ejemplo, el principio está previsto en normativa general en el art. $4^{\circ}$, VII, de la Ley n. 6.938/81 - da Política Nacional do Meio Ambiente -, y en el art. 225, § 3o- de la Constitución Federal. Por su parte, en Costa Rica, el principio no está expresamente previsto en la Constitución Política, pero está contemplado en la legislación infraconstitucional, concretamente en la Ley Orgánica del Ambiente (n. 7554, art. 2o d). ${ }^{2}$ Cabe indicar que esas normas hacen

1 Dicho principio es más conocido en la doctrina de habla hispana como principio "Quien contamina paga", y en la doctrina de habla portuguesa como principio do "poluidor-pagador". En el presente trabajo se optó por denominarlo como principio del causante, por considerar más adecuada esa denominación para el caso de instrumentos económicos de gestión ambiental. Lo anterior, debido a que, de acuerdo a la finalidad de esos mecanismos, entre ellos el tributo, no se pretende establecer un derecho a contaminar por medio de un pago, ni tampoco una responsabilidad por daño causado, sino que lo que se busca es adoptar mecanismos capaces de disuadir actividades y conductas que puedan impactar el ambiente, pero dentro de los límites de tolerancia de la naturaleza, y no cuando ya se llega al punto de degradación o contaminación, en cuyo caso se exige la aplicación de sanciones y multas, determinando la responsabilidad del sujeto que degrada o contamina. Así, adoptar las otras denominaciones citadas podría provocar problemas de legitimidad a la hora de valorar la implementación de tributos ambientales.

2 Además, el Tribunal Constitucional (Sala Constitucional) lo ha reconocido como un principio que se deriva del deber de protección ambiental previsto en el art. 50 de la Constitución, y que debe orientar las políticas públicas de defensa ambiental.

Al respecto puede consultarse: Sala Constitucional de Costa Rica. Resolución n. 9.966-2010; Resolución n. 9.170-06. Disponibles en: <https://nexuspj.poder-judicial.go.cr/advancedSearch〉. Acceso en: 12 de marzo de 2020. 
Reflexiones sobre el alcance de los principios del causante y de capacidad contributiva a la luz de la teoría de la tributación ambiental: los casos de Brasil y Costa Rica

referencia a la aplicación del principio para casos de responsabilidades por daños ambientales, determinando la aplicación de sanciones penales o administrativas cuando corresponda. Es decir, en esos casos, se debe entender que el sujeto que contamina deberá responsabilizarse por el daño causado a la naturaleza. No existe disposición expresa en las constituciones políticas de Brasil y de Costa Rica que se refieran al principio del causante en la forma de tributación ambiental, de carácter extrafiscal.

Sobre el contenido del principio, es necesario resaltar que el principio del causante no debe ser entendido apenas como una orientación de no subsidio, en el entendido de que se opone a los beneficios fiscales otorgados a sujetos que contaminan. Se trata también de un principio activo y dinámico que parte del presupuesto de que los agentes económicos que tienen poder de control sobre el impacto humano sobre la naturaleza deben tomar las medidas pertinentes para reducir ese impacto al mínimo posible.

De acuerdo con ese razonamiento, el principio del causante orienta posibles respuestas a los problemas de las externalidades ambientales y su objetivo principal es que los costos sociales provocados por actividades que impacten el ambiente - externalidades negativas- repercutan sobre los productos y servicios ligados a esas actividades. Podría afirmarse que se trata de un principio de justicia distributiva, cuyo objetivo es que la sociedad no sea obligada a soportar los costos necesarios para mantener los índices de calidad ambiental. El principio exige la internalización de los costos ambientales, una vez que parte de la idea de que ningún individuo o agente deberá lucrar a costa de la sociedad. A contrario sensu, entendemos que debe interpretarse que aquellos que con sus conductas críen condiciones específicas de protección ambiental que beneficien a la sociedad, deberán recibir un incentivo o compensación justa, internalizándose así las externalidades ambientales positivas (ROSEMBUJ, 1998, p. 53).

El principio del causante permite identificar el agente que podrá impactar el ambiente natural. Maria Alexandra de Sousa Aragão (1997, p. 136) considera que, de acuerdo con ese principio, el que debe pagar es aquel que tiene poder de control sobre las condiciones que llevan a provocar impacto ambiental, pudiendo prevenirlas o tomar precauciones para evitar que sucedan. Así, el causante pasa a ser el primero que debe asumir la responsabilidad ante la externalidad ambiental negativa provocada, teniendo la obligación de integrar, en su proceso de decisión, la señal económica que constituye el conjunto de costos ambientales

Para Paulo Henrique do Amaral (2007, p. 116),

\begin{abstract}
[...] sempre terá que se buscar imputar ao poluidor o custo suportado por toda a coletividade em razão das limitações advindas com a degradação ambiental gerada pelas suas atividades econômicas. Além, é claro, de atribuir ao poluidor todas as despesas inerentes ao desenvolvimento de novos e adequados sistemas de minimização ou neutralização da poluição. Até porque o custo social gerado pela poluição vai desde o esvaziamento do conteúdo econômico da propriedade privada, passando pelas limitações das liberdades individuais, chegando ao comprometimento da qualidade de vida de toda a coletividade.
\end{abstract}

Debe resaltarse que, en el caso la tributación ambiental, por ejemplo, el principio del causante no crea un derecho de contaminación, es decir, no se trata de un peaje que permite que el agente económico que pueda pagar tenga derecho a contaminar; por el contrario, el principio pretende limitar el impacto ambiental a niveles sustentables, de la manera más eficiente posible. En otras palabras, el principio tiene una vocación preventiva y no punitiva o represiva, ya que objetiva transmitir la idea de que el impacto ambiental es económicamente perjudicial para el sujeto que desarrolla una actividad o conducta que repercute sobre la naturaleza; entendiendo que las prácticas sustentables son más adecuadas y baratas que la degradación. El posible causador de impacto ambiental será obligado a cambiar su comportamiento o disminuir la actividad 
que impacta el ambiente. De modo que, con el principio lo que se pretende es la no contaminación, y que el impacto que esté presente en la conducta o actividad, sea el mínimo posible.

Sobre los alcances del principio en materia tributaria, el profesor Ricardo Lobo Torres (2005, p.27) afirma que,

O princípio do poluidor-pagador está ligado à ideia de internalização de eventuais prejuízos ambientais, sem a qual seria repassada para terceiros a responsabilidade pela carga tributária necessária a garantir os riscos ambientais.

El principio del causante es un parámetro de justicia, que encuentra legitimidad en el valor solidaridad, teniendo una estrecha relación con los principios precautorio, preventivo y de responsabilidad.

El principio será eficaz en la medida en que permita una adecuada internalización de las externalidades ambientales; y será equitativo si logra imputar los costos del impacto ambiental al agente responsable. La efectividad será más fuerte si los precios lograr reflejar realmente los costos ambientales y su incidencia en la gestión ambiental. Para cumplir esa finalidad, es necesario que la previsión de internalizar las externalidades ambientales sea realizada a lo largo de todo el proceso de vida del bien o servicio, es decir desde en todas las etapas: extracción, producción, transporte, consumo y tratamiento de residuos.

Pese a las consideraciones realizadas, en el fondo, la determinación del causante será una decisión de política ambiental, en la cual deberán ser considerados criterios tanto de carácter técnico (económico, administrativo y de eficacia ambiental) como político jurídico. Al respecto, la profesora Cristiane Derani (2005, p. 648-649) explica:

Poluidores são todas aquelas pessoas - integrantes de uma corrente consecutiva de
poluidores - que contribuem com a poluição ambiental, pela utilização de materiais
danosos ao ambiente como também pela sua produção (inclusive os produtores de
energias) ou que utilizam processos poluidores. O endereçamento de medidas a um
integrante desta 'comunidade de poluidores' não pode ser deduzido automaticamente
do princípio do poluidor-pagador, porém precisa (e pode) ser deduzido de pontos de
vista políticos (por exemplo, efetividade de objetos, eficiência econômica, gastos ad-
ministrativos etc.).

Para el tratadista español, profesor Ramón Martín Mateo (1991, p. 240), el principio del causante es una condición de legitimidad del tributo ambiental. El principio orienta las políticas públicas en materia ambiental, pudiendo ser proyectado sobre el sistema tributario, incentivando, no exigiendo, la creación de tributos ambientales. Del principio del causante se derivan los principios del consumidor/pagador y costo/beneficio, que se aplican a los tributos de contraprestación y a los precios públicos.

El principio del causante fundamenta y orienta la extrafiscalidad ambiental con el objetivo de permitir una eficiente reducción de los impactos ambientalmente negativos causados por determinadas actividades, hasta lograr alcanzar niveles adecuados y sustentables. Por medio de la extrafiscalidad, el Estado pasa a utilizar la técnica tributaria como un instrumento de regulación que le permite intervenir en la dirección de la actividad económica con el objetivo de alcanzar objetivos en beneficio de la colectividad.

Así, actualmente se entiende que la tributación, además de ser un instrumento destinado a financiar los gastos públicos -finalidad fiscal-, puede cumplir también una importante finalidad de carácter extrafiscal -ordenadora. Es importante indicar que los tributos no son puramente fiscales o extra fiscales, sino que ambas finalidades se complementan y están presentes en mayor o menor grado en todo tributo. En algunos casos prevalecerá la finalidad recaudatoria y en otros la ordenadora. Como afirma Casado Ollero (1991, p. 104), se trata de dos caras de la misma moneda. Sobre el tema, Paulo Carvalho de Barros (2000, p. 230) explica: 
Reflexiones sobre el alcance de los principios del causante y de capacidad contributiva a la luz de la teoría de la tributación ambiental: los casos de Brasil y Costa Rica

Há tributos que se prestam, admiravelmente, para a introdução de expedientes extrafiscais. Outros, no entanto, inclinam-se mais ao setor da fiscalidade. Não existe, porém, entidade tributária que possa se dizer pura, no sentido de realizar tão só a fiscalidade, ou, unicamente, a extrafiscalidade.

\subsection{Técnicas tributarias para el desarrollo de la extrafiscalidad. Tributación ambiental en sentido amplio y en sentido estricto}

Doctrinariamente, la introducción de la variable ambiental en el sistema tributario puede darse de dos maneras: 1. Tributos ambientales en sentido amplio - o sentido impropio; y 2. Tributos ambientales en sentido estricto - o sentido propio (HERRERA MOLINA, 2000, p. 55).

Podríamos afirmar que ambas técnicas responden al principio del causante, ya que ese principio exige la reducción de impactos ambientales, sea por medio de la internalización de externalidades ambientales negativas -a través de las cargas tributarias- o por medio de medidas que reconozcan y promuevan prácticas sustentables que provoquen externalidades ambientales positivas.

1. Tributación ambiental en sentido amplio (impropio). En este caso, se da la introducción de elementos ambientales en los tributos ordinarios, de finalidad fiscal. En este supuesto, el instrumento tributario tiene una finalidad predominantemente recaudadora, no obstante, en alguno de sus elementos existe un elemento ecológico. Por ejemplo, en el caso de vinculación de ingresos tributarios con destinos ambientales específicos, incentivos fiscales para actividades sustentables, etc. En este caso, se entiende que el tributo es ordinario, con finalidad fiscal, pero que tiene efectos extrasfiscales relevantes para la protección ambiental.

Tulio Rosembuj (1998, p. 55) considera que la prioridad de la tributación ambiental deberá ser la recaudación dentro del sistema tributario ordinario, con el objetivo de aplicar lo recaudado en la prevención del riesgo, daño o salud de los ciudadanos. Sin embargo, el autor español advierte que la recaudación no excluye la posibilidad de implementar un discurso extrafiscal que pretenda modificar la conducta de aquellos que tienen el poder de adoptar cambios en la producción, tecnología y consumo, con la finalidad de minimizar la contaminación, racionalizar el uso de energía, preservar y utilizar de forma racional los recursos naturales y reducir o reutilizar los residuos, ect.

La autora portuguesa Cláudia Dias Soares (2002, p.13-14) explica que la tributación ambiental en sentido amplio,

[...] têm como objectivo primeiro a obtenção de receitas a aplicar em projetos de defesa ecológica, impostos ambientais em sentido impróprio. "Em sentido impróprio" porque o objetivo é a captação de meios a utilizar na realização da política ecológica, eles serão, em princípio, tão ambientais, quanto qualquer outro tributo que permita recolher meios financeiros para a prossecução do fim em causa. Só se distinguindo o seu contributo para o equilíbrio ecológico do dos impostos fiscais em geral quando, sem deixarem de apresentar como primeira finalidade a captação de receitas, e não o estímulo à adoção de condutas mais sustentáveis, tenham por objeto situações ou atividades que causem dano ao ambiente, internalizando as externalidades. Esta espécie de tributos relega, assim, para segundo plano aquela que deve ser a principal via de tratamento do problema ecológico: a prevenção.

2. Tributación ambiental en sentido estricto (propio). En este supuesto, se entiende que un tributo es verde cuando existe un vínculo entre su estructura y el impacto causado en el ambiente; es decir, la figura tributaria deberá producir un (des)incentivo que permita satisfacer la finalidad ambiental pretendida (BUÑUEL GONZÁLEZ, 2008). 
Domingo Carbajo Vasco y Pedro Herrera Molina (2004) explican que la fiscalidad ambiental en sentido amplio comprende tanto el establecimiento de tributos destinados a proteger el ambiente como las medidas fiscales incorporadas a la regulación de tributos ordinarios con algún efecto ambiental. Sin embargo, advierten que desde una perspectiva tributaria, solo podrá ser calificado como tributo ambiental stricto sensu, aquel cuya estructura establezca un incentivo para la protección de la naturaleza, de forma que las externalidades externas derivadas del impacto ambiental sean asumidas por el causante. Así, por ejemplo, un tributo cuya única nota ambiental se relacione con el destino de los ingresos obtenidos, no presenta ningún tipo de especialidad desde la perspectiva del derecho tributario.

Pedro Herrera Molina (2000, p. 61) considera que

[...] sólo son impuestos ecológicos aquellos con fines de ordenamiento o extrafiscales. Como señala la Comunicación de la Comisión Europea sobre Impuestos y gravámenes ambientales en el mercado único, "una característica habitual para que una exacción determinada se considere de carácter ambiental sería que la sustancia o actividad gravada [objeto imponible] tenga un efecto negativo claro sobre el medio ambiente.

De modo que, para que un tributo pueda ser considerado como ambiental en sentido estricto, no es suficiente que aparezca esa denominación en la ley. Lo que permite calificar un tributo ambiental en sentido propio es su estructura. Así, por ejemplo, el impuesto sobre la renta no podrá ser considerado tributo ambiental en sentido estricto, por el simple hecho de que un porcentaje de los ingresos recaudados se destinado a una finalidad ambiental (BUÑUEL GONZÁLEZ, 2004, p. 42).

Sobre el tema, Gloria Alarcón García (2002, p. 267) expresa que: “(...) un tributo no puede calificarse como ambiental por el mero hecho de destinar los recursos obtenidos a una mejora del medio ambiente, ya que si se aceptara esta posibilidad cualquier tributo podría ser calificado como tal, siempre y cuando su recaudación se vinculara a la conservación, mejora o protección del ambiente".

Pese a las diferencias teórico-prácticas indicadas, tanto la finalidad extrafiscal del tributo en sentido estricto, como los efectos extrafiscales de tributos ordinarios son importantes, en la medida en que se trata de mecanismos que se complementan. No obstante, consideramos que los efectos extrafiscales de los tributos ordinarios, por sí solos, son incapaces de provocar un incentivo real para que los agentes económicos orienten sus actividades de manera sustentable; esos incentivos deben necesariamente ser complementados con tributos extrafiscales en sentido estricto y con otros instrumentos económicos de gestión ambiental.

\subsection{El principio del causante y la estructura del tributo con finalidad extrafiscal}

El principio del causante exige una estrecha relación entre el hecho generador y el elemento cuantitativo del tributo, es decir, el impacto ambiental tributado deberá ser calculado y reflejado sobre el monto del tributo. Ese vínculo permitirá determinar la eficacia del tributo ambiental.

En ese sentido, el principio del causante caracteriza al tributo ambiental como de carácter selectivo, una vez que incide sobre hechos económicos que impactan de manera negativa sobre el ambiente. Consecuentemente, el tributo verde podrá gravar una actividad económica y no otra, a pesar de que se traten de empresas del mismo ramo, que las rentas sean similares, o que esas 
Reflexiones sobre el alcance de los principios del causante y de capacidad contributiva a la luz de la teoría de la tributación ambiental: los casos de Brasil y Costa Rica

empresas contribuyan económicamente con distinta intensidad. El criterio de diferenciación será el tipo de relación de los agentes económicos con el ambiente y no su capacidad contributiva. Ese trato diferenciado no quebranta el principio de igualdad tributaria cuando el mismo es justificado por una finalidad ambiental debidamente fundamentada de acuerdo un análisis de proporcionalidad. De modo que, el hecho generador del tributo ambiental stricto sensu deberá ser definido considerando las actividades impactantes que pretenden ser desestimuladas con la carga tributaria. Deberá ser tributada una situación que tenga relación con la internalización de externalidades ambientales negativas y no con la capacidad contributiva del sujeto pasivo.

En lo que respecta a las especies tributarias, el Modelo de Código Tributario para América Latina, por ejemplo, establece que los tributos ambientales son aquellos impuestos, tasas, contribuciones o figuras de carácter híbrido que presentan como hecho generador actividades y conductas que inciden negativamente en el medio ambiente o que provocan una actuación pública de tutela ambienta (BUÑUEL GONZÁLEZ, Miguel; HERRERA MOLINA, 2003, p. 6.).

De modo que, el legislador deberá analizar, de acuerdo con criterios técnicos y de proporcionalidad, la categoría tributaria más adecuada para cada caso concreto. El uso de una u otra categoría tributaria deberá estar orientado por las características del hecho que impacta o provoca un riesgo ambiental. La tarea no es sencilla, debido a varios factores, entre ellos, la dificultad de evaluar previamente la categoría tributaria idónea para la defensa ambiental, la complicada determinación de todos los posibles hechos de carácter ambiental que pueden ser tributados, los potenciales sujetos pasivos y los problemas para determinar el quantum del tributo.

Consideramos que la tributación ambiental podrá alcanzar todas las especies de tributos y figuras tributarias de carácter mixto, siempre que en su estructura existan elementos que incentiven la protección ambiental o desestimulen su mayor impacto, orientando las actividades de los agentes económicos de forma sustentable.

El principio del causante y sus sub-principios -del consumidor/pagador y de costo/beneficio- deberán orientar la determinación del sujeto pasivo que deberá pagar el tributo. Esa identificación en la norma deberá considerar la capacidad de impacto ambiental que pretende ser tributado en cada caso. Por las características de la complejidad ambiental, esa definición de sujeto pasivo no es sencilla. Técnicamente, de acuerdo con el principio del causante, podemos establecer algunos criterios para facilitar la determinación del elemento subjetivo del tributo (HERRERA MOLINA, 2008, p. 207):

1. El sujeto que realiza las emisiones (industria o consumidor final);

2. El productor de los bienes cuyo consumo genera impacto ambiental;

3. Todos los agentes que participan de la cadena de sujetos que impactan el ambiente; o

4. El sujeto que está en condiciones más adecuadas para evitar el impacto ambiental.

En cada caso concreto, el legislador deberá evaluar las características que identifican la conducta o actividad económica de relevancia ambiental que pretende ser desincentivada (de extracción, transporte, producción, consumo, desecho) con el tributo y los criterios técnicos que permitan facilitar la gestión del tributo sin desconsiderar su finalidad extrafiscal.

Por ejemplo, caso se pretenda tributar las emisiones de gases en la atmósfera de un determinado sector industrial, es claro que el elemento subjetivo del tributo deberá considerar el foco emisor de esos gases, no siendo idónea la repercusión jurídica del tributo. Por otra parte, en el caso de la tributación sobre productos, el criterio de la esencialidad y de la selectividad será fundamental con el objetivo de frenar el consumo de bienes superfluos y de impacto ambiental. 
En lo que respecta a las alícuotas, el principio del causante orienta que las mismas sean progresivas, permitiendo su aumento de acuerdo al impacto ambiental de la actividad que pretende ser desincentivada. La modulación del tributo en función del impacto ambiental es un requisito sine qua non, de modo que, a mayor impacto, mayor tributo. La progresividad es determinante como parámetro de justicia tributaria. De igual manera, de acuerdo a la extrafiscalidad, el establecimiento de reducciones o inventivos deberá responder a la modificación de conductas de los agentes económicos.

Siguiendo la orientación del principio del causante, el tributo deberá discriminar los agentes económicos que pueden reducir el impacto ambiental con un costo menor que aquellos que tienen dificultades. Así, deberá pensarse en tributos con alícuotas únicas para problemas ambientales uniformes y variables para problemas no uniformes.

La valoración jurídica de un tributo con finalidad extrafiscal deberá necesariamente estar precedida de una memoria técnica económica-ambiental que identifique la internalización de los costos ambientales que se pretenden corregir y que permita adaptar la estructura del tributo al principio del causante.

Evidentemente, el carácter del principio del causante parece indicar que lo adecuado es que exista un vínculo directo entre los ingresos recaudados por los tributos ambientales y la protección de la naturaleza; vínculo que en la práctica deberá concretizarse a través de fondos específicos para garantizar la sustentabilidad ambiental; ello permitiría el respeto del principio del causante y daría mayor legitimidad a la extrafiscalidad ambiental.

Cabe resaltar que el principio del causante determina que la finalidad extrafiscal ambiental busca salvaguardar la libertad, por lo que su campo de acción se encuentra dentro del ámbito de lo lícito, no teniendo carácter sancionador. En otras palabras, el principio del causante no permite el establecimiento de tributos sobre ilícitos, es decir, en situaciones en donde lo que se provoca es un daño ambiental y no un impacto ambiental. Evidentemente, serán criterios técnicos los que permitirán determinar cuando el hecho deberá ser considerado ilícito o no (AMARAL, 2007).

Pese a las diferencias teórico-prácticas indicadas, reiteramos que consideramos que tanto la finalidad extrafiscal del tributo en sentido estricto, como los efectos extrafiscales de tributos ordinarios son importantes, en la medida en que se trata de mecanismos que se complementan.

\subsection{Reflexiones sobre la posibilidad de la introducción expresa del principio del causante en las constituciones políticas de Brasil y Costa Rica}

De la lectura de las constituciones políticas de Brasil y Costa Rica, es posible observar que ninguna de las dos contempla expresamente el principio del causante como parámetro orientador para una política fiscal verde. Al respecto, de acuerdo con el contenido del principio, se considera conveniente, aunque no estrictamente necesario, incluir un dispositivo que establezca que la tributación podrá ser instrumento de defensa ambiental. Ello permitiría dar una mayor legitimidad para, de acuerdo con la teoría del doble dividendo ${ }^{3}$, introducir de forma paulatina y

3 Al respecto Acquatella (2005, p. 37) explica que: "La noción de "doble dividendo" de una reforma fiscal tiene su origen en la posibilidad de reducir impuestos distorsionantes que presentan un más alto "exceso de carga tributaria" (impuestos a la nómina, contribuciones al seguro social, otros) y de reemplazarlos por otras fuentes de recaudación cuyo "exceso de carga tributaria" es menor, como los impuestos ambientales. El "doble dividendo" de una maniobra fiscal de este tipo radicaría en que permite promover una mejoría de la calidad ambiental y, al mismo tiempo, estimular 
Reflexiones sobre el alcance de los principios del causante y de capacidad contributiva a la luz de la teoría de la tributación ambiental: los casos de Brasil y Costa Rica

sistemática la variable ambiental en los sistemas tributarios de ambos países. De igual forma, esa reforma tiene que contemplar que la extrafiscalidad ambiental deberá estar orientada por los principios de selectividad, progresividad y esencialidad ambiental.

En el caso de Brasil, podría ser introducido un párrafo al art. 145 de la Constitución Federal, adoptando una redacción similar a la propuesta realizada anteriormente por el Ministerio del Medio Ambiente (MARGULIS; MOTTA, 2000, p.16):

\begin{abstract}
$\S 3^{\circ} \mathrm{A}$ lei, de acordo com o principio do poluidor-pagador, adotará política tributária como instrumento de defesa do meio ambiente (art. 225), admitida a instituição de contribuição de intervenção ambiental. A tributação ambiental deverá estar orientada pelos princípios da seletividade, da essencialidade ambiental e da progressividade.
\end{abstract}

Por su parte, en el caso de Costa Rica, sería conveniente introducir un inciso 13 bis) al art. 121 de la Constitución Política, con una redacción similar a la propuesta para la reforma de la Constitución Federal de Brasil:

\begin{abstract}
Art 121.13) bis. A través de la ley, de acuerdo con el principio del causante de impacto ambiental, la Asamblea Legislativa podrá adoptar políticas de carácter tributario como instrumento para la defensa del medio ambiente, admitiéndose la creación de tributos ambientales. La tributación ambiental deberá estar orientada por los principios de progresividad, selectividad y esencialidad ambiental.
\end{abstract}

Ambas reformas permitirían dar una mayor legitimidad a los tributos ambientales, permitiendo transparencia y seguridad jurídica. El principio del causante recomienda la elaboración de una normativa general que permita implementar la extrafiscalidad ambiental de una forma sistemática, clara y eficiente.

\title{
2. LOS ALCANCES Y LIMITACIONES DEL PRINCIPIO DE CAPACI- DAD CONTRIBUTIVA EN EL CASO DE LA EXTRAFISCALIDAD AM- BIENTAL
}

\subsection{Precisiones conceptuales sobre el principio de capacidad contributiva}

En el Estado de Derecho moderno, la distribución de las cargas tributarias deberá ser realizada de forma racional, proporcional y equitativa, conforme a la idea de justicia distributiva aristotélica, que en el derecho tributario moderno se manifiesta a través del principio de capacidad contributiva. De acuerdo con ese principio de justicia tributaria material, las cargas tributarias deberán ser establecidas de acuerdo con la riqueza de cada contribuyente, es decir, considerando las posibilidades de cada ciudadano para contribuir con los gastos públicos.

Según ese principio, deberá entenderse que el justo distributivo tributario -medio término aristotélico- será alcanzado si cada uno paga aquello que le corresponde, conforme a una proporcionalidad participativa, de modo que se evite el exceso de pago y la falta de contribución (BITTAR, 2005, p.120)

La capacidad contributiva puede ser considerada como una medida racional para determinar la carga fiscal que deberá soportar cada contribuyente. El principio es presupuesto -obje-

la generación de nuevos empleos al reducir otros impuestos que aumentan la carga tributaria asociada a la mano de obra, lo que de hecho implica una disminución del costo laboral". 
tivo y subjetivo-; y a su vez parámetro del tributo. Como presupuesto objetivo, el principio impone al legislador la obligación de adoptar un hecho generador de contenido económico relevador de ganancia. Como presupuesto subjetivo, el principio determina que cada contribuyente deberá poseer recursos económicos suficientes que le permitan soportar la carga tributaria sin que se vea afectado su mínimo existencial, ni sean confiscados sus bienes. Finalmente, como parámetro, la capacidad contributiva está relacionada con la graduación del tributo.

Como principio de justicia distributiva, se entiende que a la hora de establecer el hecho generador del tributo, el legislador deberá tener presente la condición diferenciada de cada ciudadano - capacidad contributiva-, como criterio para determinar la justa distribución del tributo. Al respecto, el profesor Ricardo Lodi Ribeiro (2003, p. 61) explica que ese principio no representa apenas un límite negativo que excluye hechos que no revelen una manifestación de riqueza, sino que, además, se trata de un criterio indispensable para distribuir la carga tributaria entre los ciudadanos.

El principio tiene una estrecha relación con el principio de igualdad tributaria, entendiéndose que el tributo deberá ser establecido en términos iguales para todos aquellos contribuyentes que tengan una misma capacidad contributiva. De modo que existirá una distribución injusta de las cargas tributarias cuando, desconsiderando la capacidad contributiva, exista exceso de carga para unos y escasez de tributo para otros.

El principio de capacidad contributiva es criterio de aplicación de igualdad, que busca contenido en ese valor y en el derecho de pagar tributo en la misma proporción de aquel que posee la misma riqueza. Se trata de una manifestación de igualdad proporcional y constituye una exigencia de justicia tributaria, garantizando la proporcionalidad y la razonabilidad de los tributos. En tesis, debemos entender que existirá igualdad si el tributo grava condiciones iguales de capacidad contributiva, es decir, cuando el mismo tiene el mismo peso para todos los contribuyentes, lo que solo será posible si su monto varía, en la medida en que considere la capacidad contributiva de cada sujeto (WEISS, 2006, p. 174). Así, el principio tiene como finalidad establecer la justicia distributiva tributaria, lo que podemos traducir, en otras palabras, en la igualdad proporcional $^{4}$.

La capacidad contributiva está sujeta a limitaciones cuantitativas, como es el caso de la prohibición de exceso -confiscatoriedad-, y del mínimo existencial. También está limitada por restricciones cualitativas - caso de las prohibiciones de desigualdad.

Por otro lado, el principio de capacidad contributiva tiene una relevante función de carácter interpretativo, ya que permite determinar si una norma tributaria quebranta la proporcionalidad aristotélica. Consecuentemente, será competencia de los tribunales de justicia determinar, en cada caso concreto, de acuerdo con ese principio, si la norma tributaria hace una justa distribución de las cargas.

Debe resaltarse que el principio es de aplicación, en mayor o menor medida, a todas las especies tributarias, ya que todos los tributos pretenden obtener recursos económicos de los contribuyentes para poder sufragar los gastos públicos. Así, todos los hechos generadores revelan un acto que revela un contenido económico.

4 Sobre el tema, el professor Ricardo Lodi Ribeiro (2003, p. 65 )afirma: “O princípio da capacidade contributiva constitui-se em uma decorrência da igualdade, na medida em que todos devem contribuir para as despesas públicas, em razão das suas possibilidades econômicas. Assim, de acordo com essa diretriz, somente são legítimas as distinções que se baseiam na diferença entre as riquezas que vários contribuintes manifestam". 
Reflexiones sobre el alcance de los principios del causante y de capacidad contributiva a la luz de la teoría de la tributación ambiental: los casos de Brasil y Costa Rica

El principio de capacidad contributiva está previsto expresamente en el art. $145, \S 1^{\circ}$, de la Constitución Federal de Brasil ${ }^{5}$. En el caso del ordenamiento jurídico de Costa Rica, el principio no está expresamente previsto en la Constitución; no obstante, el Tribunal Constitucional (Sala Constitucional) ha manifestado en su jurisprudencia que se trata de un principio constitucional tributario que se deriva de la lectura del art. 18 de la Constitución ${ }^{6}$.

Hechas esas consideraciones generales del principio en lo que respecta a la finalidad fiscal del tributo, cabe preguntarse cuál será su alcance en el caso de la extrafiscalidad, concretamente, cuando la misma está enfocada para finalidades ambientales.

\subsection{Alcances del principio de capacidad contributiva en la tributación am-}

\section{biental}

Conciliar extrafiscalidad y capacidad contributiva es un tema polémico que ha provocado un intenso debate doctrinario. Sin duda, se trata de uno de los aspectos más controversiales en el campo de la tributación ambiental, principalmente en los que respecta a la figura del impuesto. En el caso de las tasas y de las contribuciones, el asunto resulta ser menos complicado, ya que esos tributos -de carácter contraprestacional- responden a un principio de equivalencia.

Borrero Moro (1999, p.93) explica que la proyección del principio de capacidad contributiva en la extrafiscalidad ambiental es compleja, y abarca diversos aspectos de la tributación ambiental. Explica el autor español que el principio afecta de modo singular la identificación del verdadero aspecto material que pretende tributarse.

En el caso del ordenamiento jurídico brasileño, por ejemplo, considerando la expresión utilizada por el constituyente en el art. 145 de la Constitución Federal, "siempre que sea posible", algunos autores afirman que el principio de capacidad contributiva puede no aplicarse a la tributación ambiental ${ }^{7}$.

Por otro lado, sobre el tema, parte de la doctrina considera que la contradicción que podría existir entre ese principio y la tributación ambiental es apenas aparente, ya que esos tributos gravan actividades que evidentemente denotan una capacidad de producir riqueza (Borrero Moro, 1999, 95 y 136). En ese sentido, estiman que la capacidad de impactar el ambiente en beneficio de determinados intereses económicos es un indicio notorio de la existencia de capacidad económica $^{8}$. Así, sustentan que el hecho generador de esos tributos debe necesariamente

5 “\$ 1- Sempre que possível, os impostos terão caráter pessoal e serão graduados segundo a capacidade econômica do contribuinte, facultado à administração tributária, especialmente para conferir efetividade a esses objetivos, identificar, respeitados os direitos individuais e nos termos da lei, o patrimônio, os rendimentos e as atividades econômicas do contribuinte."

6 Al respecto, pueden consultarse los votos de la Sala Constitucional: n. 4.788-93 y 4.829-98. Disponibles en: https://nexuspj.poder-judicial.go.cr/advancedSearch. Acceso en: 12 de marzo de 2020.

7 Sobre el asunto, el tributarista Luciano Amaro (2001, p. 134) indica que “(...) ‘sempre que possível' - como diz a Constituição -, o imposto deve levar em consideração a capacidade econômica do contribuinte. A expressão 'sempre que possível' cabe ressalva tanto para a personalização como para a capacidade contributiva. Dependendo das características de cada imposto, ou da necessidade de utilizar o imposto com finalidades extrafiscais, esses princípios podem ser excepcionados."

En el mismo sentido, Humberto Ávila (2006, p. 367) afirma que “(...) o essencial é que a expressão não traduz uma permissão, mas um dever cujo significado depende da possibilidade, jurídica e ontológica, da graduação de acordo com a capacidade econômica do contribuinte. A expressão 'sempre que possível' abre expressamente a possibilidade de instituição de tributos extrafiscais".

8 Sobre el tema Rosembuj (1995, p. 245, 261-262) explica que en la fiscalidad ambiental, el tributo "se basa en el presupuesto de la existencia objetiva de una capacidad contaminante potencial o real que, necesariamente, debe calificar su hecho imponible. El criterio ambiental de la legitimidad y justificación del tributo tiene como soporte el de 
tributar una potencial manifestación de riqueza que se deriva de la posibilidad de aprovechar bienes naturales. Borrero Moro (1999, p. 94-97) se adhiere a esa tesis, indicando la existencia de una renta potencial que se deriva del impacto ambiental. Para él, la fuerza económica que legitima el tributo no se deriva de la capacidad del agente económico de intervenir o no en el ambiente, sino de la manifestación de actividades económicas que provocan impacto sobre la naturaleza9.

Distinto es nuestro criterio, ya que, conforme expuesto en la primera parte de este trabajo, consideramos que de acuerdo con el principio del causante, el tributo ambiental deberá estar vinculado a una actividad de impacto sobre el ambiente - extracción, producción, transporte, consumo, descarte. Sostenemos que el objeto del tributo verde está directamente ligado a la capacidad de impacto sobre la naturaleza. Es decir, el tributo no pretende gravar un índice potencial de riqueza, y en ese entendido no está orientado por el principio de capacidad contributiva.

Sostenemos que el hecho de impactar el ambiente no puede ser considerado, por sí mismo, un indicador de riqueza. Lo anterior bajo el argumento de que si el causante podrá obtener o no algún beneficio económico a partir del uso del ambiente, es un tema que no está relacionado directamente con el hecho generador del tributo. El hecho generador y la estructura cuantitativa de los impuestos ambientales no responden a la capacidad contributiva del contribuyente, sino más bien a una modalidad específica del principio de equivalencia: el principio del causante. Así, su justificación está en el impacto provocado en la naturaleza ${ }^{10}$.

De manera que, el tributo ambiental, fundamentado en el principio del causante, no deberá ser calculado considerando la riqueza del agente económico, y sí el impacto o riesgo ambiental causado por la actividad económica. El punto de partida para que se configure el tributo no deberá ser monetario, ya que, de hacerlo de esa forma, podrá contrariar el principio de igualdad, tributando de la misma forma sujetos que impactan el ambiente con una intensidad diferente. En ese sentido, la renta y el patrimonio no son índices de impacto ambiental. Así, por ejemplo, una empresa puede haber lucrado más que otra del mismo sector, pero con menos impacto negativo sobre el medio ambiente (BAENA AGUILAR, 2002, p. 197-198); o actividades económicas de dos empresas del mismo ramo con condiciones patrimoniales similares podrán tener consecuencias diferentes en el ambiente, de manera que no sería justo que soporten la misma carga tributaria.

quien contamina paga, que sirve para denotar la capacidad contaminante y para connotar su contenido económico y social (solidaridad colectiva) de cara al deber de contribuir al gasto público, conforme a la capacidad económica.

(...) el tributo ambiental encauza la financiación del gasto social conforme a la capacidad económica, y para discriminar entre los que exhiben más o menos capacidad de contaminar, más o menos capacidad de descontaminar el bien ambiente.

(...) La capacidad económica tiene una connotación inseparable con el principio de quien contamina paga, en el fundamento y origen del Derecho ambiental. El objeto del tributo se configura en base a la existencia objetiva de una capacidad contaminante potencial o real, que indica capacidad económica, sea como manifestación de renta, patrimonio o consumo".

9 Posición similar es adoptada por Pablo Chico de la Cámara (2008, p. 171).

En Brasil, esa tesis es adoptada por Domingues de Oliveira (2007, p. 22), quien considera que "não se descure da questão, tão fundamental quanto árdua, da conciliação do princípio da capacidade contributiva com a extrafiscalidade. Equivocadamente negada por uns, impende dar curso à aludida harmonização através da identificação de fatos geradores que a um só tempo indiciem, pela apreensão ou aproveitamento dos bens naturais, manifestações de riqueza suscetíveis de tributação e justifiquem uma ponderada participação dos agentes econômicos no rateio dos custos de manutenção do Estado (...)”.

${ }^{10}$ En ese mismo sentido, puede consultarse a: SOLER ROCH, M. T. El principio de capacidad económica y la tributación medioambiental. In: BECKER, Fernando; CAZORLA, Luis María et al. (dirs.). Tratado de tributación medioambiental. v. I. Pamplona: Aranzandi, 2008; y HERRERA MOLINA, Pedro M. EI Principio "quien contamina paga”. In: BECKER, Fernando; CAZORLA, Luis María et al. (dirs.). Tratado de tributación medioambiental. v. I. Pamplona: Aranzandi, 2008. 
Reflexiones sobre el alcance de los principios del causante y de capacidad contributiva a la luz de la teoría de la tributación ambiental: los casos de Brasil y Costa Rica

Partiendo de esa tesis, sostenemos que la modulación del tributo ambiental deberá ser establecida de acuerdo con la orientación del principio del causante, considerando el impacto que el sujeto pasivo causa en la naturaleza, utilizando criterios de proporcionalidad y de equivalencia. Por ejemplo, en el caso de impuestos que gravan la emisión de substancias contaminantes en la atmósfera (dióxido de carbón, azufre, o nitrógeno, entre otros), la emisión de esas substancias denota una capacidad de contaminar, pero en sí misma no representa una riqueza real o potencial que pueda ser considerada como una manifestación de capacidad contributiva. Es por ello que entendemos que el principio de capacidad contributiva cede ante la extrafiscaliad ambiental. El hecho generador y la modulación del tributo serán orientados y determinados en función del principio del causante y no del principio de capacidad contributiva como sucede en el caso de los tributos de finalidad predominantemente fiscal.

No obstante lo indicado, son necesarias algunas consideraciones adicionales para entender el alcance del principio de capacidad contributiva en la tributación verde.

Pese a que lo instrumentos tributarios ambientales tienen finalidades extrafiscales, también podrán tener, de forma subsidiaria, un efecto recaudatorio, cuando se configure el hecho generador. De manera que, podemos afirmar que la capacidad contributiva deberá reflejarse al materializarse el tributo verde, ya que el contribuyente deberá poseer capacidad económica para soportar la carga tributaria, sin que sea afectado el mínimo existencial o transgredido el principio de no confiscatoriedad. Es decir, dicho en otras palabras, en caso de que se configure la actividad o conducta que pretende ser desestimulada. En el cobro del tributo deberá existir una capacidad contributiva que permita el cobro del gravamen. En ese sentido, puede afirmarse que todos los tributos, tanto fiscales, como extrafiscales, deben cumplir una exigencia mínima de capacidad contributiva.

Siguiendo esa tesis, Bokobo Moiche (2000, p.88) explica que la capacidad contributiva no está en la base del tributo, sin embargo, sirve de criterio de valoración, permitiendo determinar el quantum del impuesto. En igual sentido, Cláudia Dias Soares (2002, p.43) señala que la capacidad contributiva del sujeto no puede ser dejada de lado a la hora de determinar el cálculo del tributo, como límite máximo y mínimo de la carga; además constituye elemento que permite auxiliar la determinación del monto de la obligación tributaria siempre que se muestre relevante para su eficacia ambiental. De modo que, el principio del causante no excluye la aplicación del principio de capacidad contributiva, una vez que este último lo modula y complementa.

Las limitaciones existentes al principio de capacidad contributiva, existentes en el caso de la tributación ambiental, son admisibles cuando la finalidad extrafiscal está expresamente reconocida en la Constitución. Es decir, cuando la Constitución ${ }^{11}$ reconoce la relevancia de tutelar jurídicamente la calidad ambiental. Sin embargo, la limitación al principio de capacidad contributiva deberá responder a criterios de proporcionalidad y estar sometida a un triple control (HERRERA MOLINA, 2000, p. 163; CHICO DE LA CÁMARA, 2008, p. 172-178):

1. Evaluación de la idoneidad del tributo y del objetivo ambiental presente;

2. Control de necesidad. Deberá determinarse si no existen otras medidas igualmente eficaces y económicamente más eficientes que permitan alcanzar los mismos objetivos ambientales con menor repercusión sobre los derechos de los individuos; y

3. Evaluación de la proporcionalidad en sentido estricto. Los intereses ambientales deberán ser objeto de una ponderación con respecto a la limitación del principio de capacidad contributiva.

${ }^{11}$ Caso de la Constitución Federal de Brasil, en su art. 225, y de la Constitución Política de Costa Rica, en el art. 50. 
En síntesis, entendemos que en el caso de la extrafiscalidad ambiental el principio de la capacidad contributiva es un presupuesto subjetivo, es decir, el contribuyente deberá tener recursos económicos que le permitan asumir la carga tributaria, sin que se afecte su mínimo existencia, ni sean confiscados sus bienes. De lo contrario, el tributo perderá su finalidad, y pasará a tener carácter sancionatorio.

Existe una exigencia mínima de capacidad contributiva en todo tributo y, consecuentemente, el tributo ambiental, como cualquier otro, debe respetar ese principio. Lo que existe en el caso de la extrafiscalidad ambiental es una cuestión de intensidad en la aplicación del principio; no se trata de entrar en una contradicción de principios, sino que debe entenderse que cada uno opera en planos diferentes, pero no de forma excluyente, sino complementaria. La extrafiscalidad no puede legitimar la creación arbitraria de un tributo que no respete la capacidad contributiva, de lo contrario tendría vicios de constitucionalidad ${ }^{12}$.

La finalidad extrafiscal del tributo no puede justificar el uso de mecanismos desproporcionados para alcanzarla. Pese a que esa finalidad pueda modular los elementos que identifican el tributo, no podrá descaracterizar la figura como tal. Los tributos ambientales, como cualquier otro tributo, deberán estar limitados por principios tributarios de justicia tributaria formal y material y respetar el mínimo existencial y la prohibición de confiscatoriedad.

\section{CONCLUSIONES}

De acuerdo con los razonamientos expuestos, es posible concluir que el principio del causante es un parámetro orientador de políticas públicas en materia ambiental que puede ser proyectado sobre el sistema tributario, alentando - no exigiendo - la creación de tributos ambientales.

12 Cazorla Prieto (2008, p. 60) sobre el tema indica que: "Aunque se ha llegado a dudar acerca de hasta que extremo el principio de capacidad económica puede tener lugar en los impuestos medioambientales, lo cierto es que este principio no puede quedar postergado por completo (...) La cobertura constitucional de los fines extrafiscales que buscan los tributos medioambientales puede justificar la distinta protección del principio de capacidad económica en los tributos extrafiscales, pero no puede justificar su olvido, pues nos encontramos ante un principio que debe conformar la estructura de todo tributo en mayor o menor grado según los supuestos".

El profesor Gabriel Casado Ollero (1991, p. 122), sobre el asunto enseña que: “(...) si bien el legislador puede ampararse en otros principios y valores constitucionales para eximir o dejar de gravar una manifestación de riqueza susceptible de imposición, en modo alguno dichos objetivos (extrafiscales) podrían legitimar el gravamen de una riqueza situada fuera de los límites imponibles, ya que sería arbitraria e injusta la imposición que prescindiese por completo de la relativa capacidad económica de los contribuyentes. (...) no habría (...) justificación posible para la arbitrariedad que supone el gravamen - extrafiscal o no - de una situación económica no enmarcada en los límites de la imposición, o que no demuestre capacidad económica alguna".

Al comentar una resolución dictada por el Tribunal Constitucional Español sobre el tema, Gabriel Casado Ollero (1991, p. 124 y 128) indicó: "A la instrumentación extrafiscal del tributo "no se opone - añade el Tribunal - el principio de capacidad económica (...), pues el respeto a dicho principio no impide que el legislador pueda configurar el presupuesto de hecho del tributo teniendo en cuenta consideraciones extrafiscales' (FJ.13). Lo que resulta evidente, en cualquier caso, es que los fines no fiscales no podrán desconocer ni quebrar la relación constitucionalmente exigida entre imposición y capacidad económica.

(...) 5. La necesidad de que los fines no fiscales de los tributos no quiebren la relación constitucionalmente exigida entre imposición y capacidad económica, ni desfiguren la naturaleza y la esencia contributiva del tributo, como instituto jurídico constitucional, no responde a exigencias de pura ortodoxia - o estética - dogmática, sino que viene exigida además por el respeto al derecho fundamental del ciudadano a no ser gravado con detracciones patrimoniales que no se fundamenten en el ordenamiento constitucional; o en otros términos, a la necesidad de evitar la arbitrariedad del legislador en el manejo de un instituto jurídico que, como el tributo, genera relaciones jurídicas de particular incidencia en el ámbito de los derechos públicos subjetivos". 
Reflexiones sobre el alcance de los principios del causante y de capacidad contributiva a la luz de la teoría de la tributación ambiental: los casos de Brasil y Costa Rica

El principio tiene como objetivo principal que los costos sociales provocados por la actividad que impacta el ambiente repercuta en los costos finales de los productos y servicio ligados a esa actividad. El principio exige la internalización de los costos ambientales, una vez que parte de la idea de que ningún individuo o agente económico debe lucrar a costa de la sociedad. El principio del causante es una condición de legitimidad de la tributación ambiental.

El principio del causante será el parámetro para delimitar la estructura del tributo ambiental, delineando los límites del hecho generador, sujeto pasivo, y elemento cuantitativo. Además, por las características de la finalidad que persigue la tributación verde, entendemos que los ingresos eventualmente obtenidos por esas cargas fiscales deberían estar sujetos a un destino específico que permita crear un fondo verde cuyo objetivo sea el financiamiento iniciativas orientadas hacia la sustentabilidad.

La protección del ambiente a través de la tributación puede ser realizada a partir de dos técnicas complementarias: la tributación ambiental en sentido amplio de efectos extrafiscales introducción de elementos ambientales en la tributación ordinaria -, o la tributación ambiental en sentido estricto de finalidad extrafiscal.

Conforme con el contenido del principio del causante, se considera conveniente, aunque no estrictamente necesario, incluir un dispositivo en las constituciones de Brasil y Costa Rica que establezca expresamente que la tributación podrá ser instrumento de defensa ambiental. Ello permitiría dar una mayor legitimidad para la introducción paulatina y sistemática de la variable ambiental en los sistemas tributarios de ambos países.

Si bien la tributación ambiental se encuentra orientada por el principio del causante, deberá ser establecida respetando el principio de capacidad contributiva. Este último, a pesar de no poder ser considerado como parámetro de la tributación ambiental, sí deberá ser considerado como presupuesto subjetivo a la hora de establecer un tributo que pretenda gravar una actividad que impacte el ambiente. De modo que, en la tributación ambiental lo que existe es una cuestión de intensidad en la aplicación del referido principio.

La extrafiscalidad no puede legitimar la creación arbitraria de un tributo que no respete el principio de capacidad contributiva. La limitación de ese principio deberá responder a criterios de proporcionalidad.

Se sustenta que, pese a su carácter extrafiscal, la tributación ambiental deberá estar limitada por los principios constitucionales de justicia tributaria formal y material y deberá respetar el mínimo existencial y la prohibición de confisco. La tributación ambiental deberá configurarse dentro del ámbito de la licitud.

\section{REFERENCIAS}

ACQUATELLA, Jean. El papel conjunto de las autoridades fiscales y ambientales en la gestión ambiental de los países de América Latina y el Caribe. In: ACQUATELLA, Jean; BÁRCENA, Alicia (eds.). Política Fiscal y medio ambiente. Bases para una agenda común. Santiago de Chile: Naciones Unidas, CEPAL, diciembre del 2005.

ALARCÓN GARCÍA, Gloria. La fiscalidad ambiental. El fenómeno tributario y su relación con el medio ambiente. In: VICENTE GIMÉNEZ, María Teresa (coord.). Justicia ecológica y protección del medio ambiente. Madrid: Trotta, 2002.

AMARAL, Paulo Henrique do. Direito tributário ambiental. São Paulo: Revista dos Tribunais, 2007. 
AMARO, Luciano. Direito tributário brasileiro. 6. ed. São Paulo: Saraiva, 2001.

ARAGÃO, Maria Alexandra de Sousa. O princípio do poluidor pagador: pedra angular da política comunitária do ambiente. Coleção Stvdia Ivridica. Coimbra: Coimbra Editora, 1997.

ÁVILA, Humberto. Sistema constitucional tributário: de acordo com a Emenda Constitucional n. 51, de 14.02.2006. 2. ed. São Paulo: Saraiva, 2006.

BAENA AGUILAR, Ángel. La protección tributaria del medio ambiente en España. In: YABAR STERLING, Ana (dir.); HERRERA MOLINA, Pedro M. (coord.). La protección fiscal del medio ambiente. Madrid: Marcial Pons, 2002.

BANALOCHE PALAO, C. La llamada Ecotasa. In: BECKER, Fernando; CAZORLA, Luis María et al. (dirs.). Tratado de tributación medioambiental. v. II. Pamplona: Aranzandi, 2008.

BITTAR, Eduardo C. B. A justiça em Aristóteles. 3. ed. Rio de Janeiro: Forense Universitária, 2005.

BOKOBO MOICHE, Susana. Gravámenes e incentivos fiscales ambientales. Madrid: Civitas, 2000.

BORRERO MORO, Cristóbal J. La tributación ambiental en España. Madrid: Tecnos, 1999.

BUÑUEL GONZÁLEZ, Miguel. Capítulo II. In:

teoría, práctica y propuestas. Madrid: Civitas, 2004. (dir.). Tributación medioambiental:

BUÑUEL GONZÁLEZ, Miguel; HERRERA MOLINA, Pedro M. (dirs.). Modelo de Código Tributario Ambiental para América Latina (Universidad Complutense de Madrid). Madrid: Instituto de Estudios Fiscales. Ministerio de Hacienda. n. 18, 2003.

CARBAJO VASCO, Domingo; HERRERA MOLINA, Pedro M. Capítulo III. In: BUÑUEL GONZÁLEZ, Miguel (dir.). Tributación medioambiental: teoría, práctica y propuestas. Madrid: Civitas, 2004.

CASADO OLLERO, Gabriel. Los fines no fiscales de los tributos. In: Comentarios a la Ley General Tributaria y líneas para su reforma. Libro Homenaje al Dr. Fernando Sainz de Bujanda, v. I. Madrid: Instituto de Estudios Fiscales, 1991.

CAZORLA PRIETO, Luis María. Los principios constitucional-financieros en la tributación medioambiental. In: BECKER, Fernando; CAZORLA, Luis María et al. (dirs.). Tratado de tributación medioambiental. v. I. Pamplona: Aranzandi, 2008.

CHICO DE LA CÁMARA, Pablo. La regla de la no confiscatoriedad como límite a la tributación medio ambiental. In: BECKER, Fernando; CAZORLA, Luis María et al. (dirs.). Tratado de tributación medioambiental. v. I. Pamplona: Aranzandi, 2008.

COSTA RICA. Jurisprudencia constitucional. Sala Constitucional de la Corte Suprema de Justicia de Costa Rica. Disponible en: https://nexuspj.poder-judicial.go.cr/advancedSearch. Acceso en: 12 de marzo de 2020.

COSTA RICA. Resolución n. 9.966-2010.

COSTA RICA. Resolución n. 9.170-06.

COSTA RICA. Resolución n. 4.788-93.

COSTA RICA. Resolución n. 4.829-98. 
Reflexiones sobre el alcance de los principios del causante y de capacidad contributiva a la luz de la teoría de la tributación ambiental: los casos de Brasil y Costa Rica

DERANI, Cristiane. Aplicação dos princípios do direito ambiental para o desenvolvimento sustentável. In: TORRES, Heleno Taveira (org.). Direito tributário ambiental. Brasil: Malheiros, 2005.

HERRERA MOLINA, Pedro M. El Principio “quien contamina paga”. In: BECKER, Fernando; CAZORLA, Luis María et al. (dirs.). Tratado de tributación medioambiental. v. I. Pamplona: Aranzandi, 2008.

HERRERA MOLINA, Pedro M. Propuestas para la elaboración de un Código Tributario Ambiental? In: ORLANDO, Breno Ladeira Kingma et al. (coord.). Direito tributário ambiental. Rio de Janeiro: Lumen Juris, 2006.

HERRERA MOLINA, Pedro M. Derecho tributario ambiental. Madrid: Marcial Pons, Ediciones Jurídicas y Sociales, 2000.

MARGULIS, Sérgio; MOTTA, Ronaldo Seroa da; OLIVEIRA, José Marcos Domingues de. Proposta de Tributação Ambiental na atual reforma tributária brasileira. Texto para discussão n. 738. Rio de Janeiro: IPEA, junho de 2000.

MATEO, Ramón Martín. Tratado de derecho ambiental. v. I, Madrid: Trivium, 1991.

OLIVEIRA, José Marcos Domingues de. Direito tributário e meio ambiente. Rio de Janeiro: Forense, 2007.

ONU. Declaración de Rio sobre el Medio Ambiente y el Desarrollo. Rio de Janeiro, 1992. Disponible en: https://www.un.org/spanish/esa/sustdev/agenda21/riodeclaration.htm. Acceso en: 10 de marzo de 2020.

RIBEIRO, Ricardo Lodi. Justiça, interpretação e elisão tributária. Rio de Janeiro: Lumen Juris, 2003.

ROSEMBUJ, Tulio. Tributos ambientales. In: YABAR STERLING, Ana (ed.). Fiscalidad ambiental. Barcelona: Cedecs, 1998.

ROSEMBUJ, Tulio. Los tributos y la protección del medio ambiente. Madrid: Marcial Pons, 1995.

SOARES, Cláudia Alexandra Dias. O imposto ambiental. Direito fiscal do ambiente. Coimbra: Almedina, 2002.

SOLER ROCH, M. T. El principio de capacidad económica y la tributación medioambiental. In: BECKER, Fernando; CAZORLA, Luis María et al. (dirs.). Tratado de tributación medioambiental. v. I. Pamplona: Aranzandi, 2008.

TORRES, Ricardo Lobo Valores e princípios no direito tributário ambiental. In: TORRES, Heleno Taveira (org.). Direito tributário ambiental. São Paulo: Malheiros, 2005.

WEISS, Fernando Lemme. Princípios tributários e financeiros. Rio de Janeiro: Lumen Juris, 2006.

Recebido em: 24 mar. 2020.

Aceito em: 13 out. 2020. 